\title{
Hearing Beyond the Normal Enabled by Therapeutic Devices: The Role of the Recipient and the Hearing Profession
}

\author{
Gregor Wolbring
}

Received: 5 January 2011 /Accepted: 25 May 2011 / Published online: 1 June 2011

(C) The Author(s) 2011. This article is published with open access at Springerlink.com

\begin{abstract}
The time is near where 'therapeutic' bodily assistive devices, developed to mimic species-typical body structures in order to enable normative body functioning, will allow the wearer to outperform the species-typical body in various functions. Although such devices are developed for people that are seen to exhibit sub species-typical abilities, many 'therapeutic enhancements' might also be desired and used by people that exhibit species-typical body abilities. This paper presents the views of members of the World Federation of the Deaf on potential beyond speciestypical abilities enabling therapeutic assistive devices (i.e. related to hearing). Survey respondents showed support for the development and uptake of beyond normal hearing enabling devices. The views of survey respondents as clients affect hearing-enabling professions (such as audiologist and speech pathologists). The paper analyzes what guidance code of ethics of hearing enabling professions give in regards to beyond normal hearing enabling devices. This paper suggests that people labeled impaired and the professions that serve them should more involved in the enhancement discourse.
\end{abstract}

G. Wolbring $(\bowtie)$

Faculty of Medicine, Department of Community Health

Science, Program in Community Rehabilitation and

Disability Studies, University of Calgary,

3330 Hospital Drive NW,

T2N4N1 Calgary, Alberta, Canada

e-mail: gwolbrin@ucalgary.ca
Keywords Deaf · Deaf culture · Hard of hearing · Therapeutic enhancement . Hearing profession . Code of ethics

\section{Introduction}

Science and technology usage, research, and development are often articulated in terms of better and/ or more sustainable health and rehabilitation care, better health, more efficient health systems, and health and rehabilitation care delivery [1]. This affects all facets of health and rehabilitation, including understanding and scope of health and rehabilitation and expectations of health and rehabilitation clients and professionals. The discourse around health and rehabilitation traditionally is based on species-typical normative body functioning as its framework of reference [2-7]. This frame of reference is slowly changing. 'Therapeutic' bodily devices, developed to mimic species-typical body structures and expected body functioning and used by people who are labeled impaired, increasingly allow this wearer to outperform the species-typical body in various functions. The cheetah artificial legs of Paralympic athletes such as Oscar Pistorius [812], Aimee Mullins [13, 14] or Sarah Reinertsen [15] are just several examples of such enhancementenabling 'therapeutic' devices and are a harbinger of change to come. Other devices include brainmachine interfaces, bionic ear, bionic eyes, retinal 
prostheses; wheelchair control; bionic legs and arm; bionic knee; neural prostheses; speech; artificial joints, artificial muscles, bioartificial kidney, artificial liver, artificial cartilage artificial lungs, artificial discs, artificial pancreas bionic dental pulp and other areas all advancing $[1,16,17]$.

Various 'therapeutic assistive devices' are linked to restoring hearing, speaking and communication. One example of new abilities related to speech not existing in humans would be the sub-vocal speech device from Ambient Incorporate [18]. This device is capable of processing neurological information from the brain into synthesized speech allowing, among other functions, for the thought-controlled movement of a wheelchair [18]. Hearing aids and cochlear implants might outperform the normal hearing in the future $[19,20]$. Additionally, there are brain machine interfaces [16, 21-23] that may potentially change the nature of communication (e.g. communicating through computers, aka techlepathy).

A lively discourse exists around the advisability and impact of the development of artificial ears, cochlear implants and external hearing devices. This involves deaf people who want to obtain the hearing ability of the species-typical human and deaf people who feel that hearing is not an essential ability (often this population aligns with a belief in deaf culture). It includes parents (deaf and not deaf) of deaf children; hard of hearing people that want to regain their species-typical hearing; hard of hearing people who do not; professionals that are involved in informing the 'impaired' client of the devices; professionals who perform the interventions and training if needed and the ones producing the devices [24-30].

This discourse to date centers around the end goal of enabling species-typical hearing abilities-with some defending the efforts to generate speciestypical hearing abilities, and with others questioning the label of 'impairment' for the decrease in as species-typical' perceived hearing ability. The latter perceive a decrease in hearing abilities as a variation in human abilities and do not see the need to obtain species-typical hearing.

However, increasingly a narrative of body ability perception and intervention is emerging that entertains the vision of moving beyond the speciestypical. This is facilitated by availability of 'enhancement drugs' that lead to transient abilities beyond the normal (not the focus of this paper) and the increasing availability of therapeutic assistive devices that allow body abilities to move permanently beyond the species-typical. In the case of neuro-devices brain machine interfaces, sub-vocal speech, artificial hippocampus and cochlear implants/hearing aids might allow wearers to move beyond the species-typical in speech, hearing and communication abilities. The paper focuses on the possibility of deaf and hard of hearing people as potential consumers of hearing devices which enable beyond species-typical hearing abilities. These consumers might perceive beyond the species-typical hearing to be a valuable avenue to gain respect and quality of life.

Despite the changing narrative, these populations (deaf, hard of hearing people, the hearing profession, and parents of deaf and hard of hearing children) are not visible in the enhancement discourse. Indeed no real discourse exists that addresses the future possibility of beyond species-typical hearing enabled by such devices.

This paper analysis the views of members of the World Federation of the Deaf on the topic of beyond 'normal' hearing enabled by assistive devices and the use of other beyond species-typical ability enabling devices (brain machine interfaces, artificial hippocampus, artificial organs and artificial eyes, noses, arms, legs, skins, retinas and sub-vocal speech devices). Results are obtained through an exploratory, non-probability survey.

Many 'therapeutic' enhancements could also be applied to and desired by species-typical people. Neuroenhancement of the 'healthy by using medication developed for 'neuro diseases' is a reality and a recognized issue [31-40]. A recent survey of 1,427 readers of the journal Nature revealed that $79 \%$ felt that healthy people should be allowed to take cognitive enhancers [41]. One-third of respondents said they would feel pressure to give cognitionenhancing drugs to their children if other children at school were taking them [41]. Outram and Racine (2011) describe a emerging public health framework around cognitive enhancements [42].

This paper highlights the sentiments of members of the World Federation of the Deaf as to the 'nonimpaired' having access to devices that increase hearing beyond the species-typical and other beyond the species-typical enabling devices. 
Therapeutic enhancement in general and in particular the aspect that they can be used for other purposes impact many professions. A study by Banjo reports that physicians prefer to give neuroenhancements to older over younger people as the enhancement treatment of the elder is seen more as a restoration of a cognitive ability which has declined with age [43] According to Geppert (2011) enhancements are rarely discussed among psychiatrists [39]. The Ethics, Law and Humanities Committee American Academy of Neurology generated a report in 2009 with the aim,

"to provide neurologists with an overview of the ethical, legal, and social issues surrounding the use of pharmaceuticals prescribed to enhance or augment normal cognitive or affective functioning, as well as practical guidance for responding to an adult patient's request for neuroenhancement" [31].

Audiologists, logopedists, and speech pathologists are some professions that are involved with deaf and hard of hearing people that want to obtain hearing enabling devices. This paper explores possible avenues for action for hearing professions, given their codes of ethics, in regards to devices which enable beyond the species-typical hearing ability.

\section{Method}

An online delivered exploratory non-probability survey (using a combination of 23 simple yes or no, Likert scale, as well as opinion rating scale questions) was developed. Seven questions covered various demographic angles. Two questions asked whether the respondent opposed cochlear implants or hearing aids. Two questions covered the topic of sign language (not covered in this paper). Six questions covered the area of future abilities of cochlear implants and hearing aids to outperform the 'species-typical' hearing. Five questions covered non hearing related therapeutic enhancement enabling interventions. The survey received ethics approval by University of Calgary Health Research Ethics board and gained approval by members of the World Federation of the Deaf responsible for such decision. The author received the notice of approval from the executive of the World Federation of the Deaf by email. After approval was obtained the link to the survey was given to the executive director of the World Federation of the Deaf who sent the link to those holding memberships. The response rate of 71 people with a $60.6 \%$ completion rate was very low assuming that the World Federation can reach many thousand people. As a result, the survey results cannot be generalized. This was expected by staff of the World Federation of the Deaf, as the survey was in English and not in sign language. However, the potential for the survey to generate preliminary data that would provide the foundation for another more accessible survey was recognized. Data of this preliminary survey were seen to provide an avenue whereby members of local deaf and hard of hearing groups, and rehabilitation professionals linked to them, could participate in focus groups and interviews (adding qualitative data to the mostly quantitative data presented here). A database was automatically generated by Survey Monkey. Data was exported as pdf files for subsequent analysis. Frequency distribution analysis of answers were performed as well as cross tabulation analysis of the results related to the following demographics: Self perception: 'Normal'; Perception by others as and Self perception: impaired; Perception by others as impaired; I am hard of hearing and perceive it as something to be fixed; I am hard of hearing and do NOT perceive it as something to be fixed; I am deaf from birth and perceive deafness as something to be fixed; I am deaf from birth and perceives deafness within a Deaf Culture Framework (all of these perceptions were options the respondent could choose from, they could also comment on these options and give new options by adding comments but no comments were gives).

\section{Results}

\section{Demographics}

Forty-one respondents or $77.4 \%$ were from Australia; three from Canada, four from Finland, one from Ireland, Sweden, Norway, Slovenia, United States. $88.9 \%(n=48)$ were between the ages of 30 and $65.21 .8 \%(n=8)$ stated that they are hard of hearing and perceive it as something to be fixed and $18.9 \%(n=7)$ stated that they are hard of hearing and 
do NOT perceive it as something to be fixed. As for people who self identified as deaf, $18.9 \% \quad(n=7)$ believed they should be fixed and $32.2 \% \quad(n=12)$ believed in deaf culture. $8.1 \%(n=3)$ stated that they are a parent of a deaf child and believe in Deaf culture. $5.4 \%(n=2)$ stated they are a parent of a deaf child and feel their child should hear. $10.8 \%(n=4)$ stated they are a parent of a hard of hearing child and believe in Deaf culture. 5.4\% $(n=2)$ stated that they are a parent of a hard of hearing child and feel $\mathrm{s} / \mathrm{he}$ should hear better.

\section{Sentiment Towards Hearing Devices}

$N=73$ do not oppose cochlear implants for themselves or others whereas $n=18$ oppose cochlear implants for themselves or others (multiple answers possible).

$N=45$ do not oppose hearing aids for themselves or others whereas $n=2$ oppose hearing aids.

\section{Sentiment Towards Different Intervention Options}

The respondents were given these three intervention options

1) Direct changes to the hearing ability of the person through today's existing internal hearing aids such as cochlear implant

2) Direct changes to the hearing ability of the person through today's existing external non-implantable hearing aids

3) Modification of the environment to allow people to function satisfactory independent of their level of hearing

The weighted mean for option 1 was 3.51 out of 5 ; for option 2 was 4.22 out of 5 and for option 3 was 4.1 out of 5 . However, comments given by the respondents in the comment box indicates that many felt all three as equally important or that the option to choose depends on the circumstances, for example access to option 1 or 2 .

\section{Hearing Beyond the Normal}

If asked whether we should develop internal or external hearing aids that generate hearing abilities that go beyond the species-typical hearing abilities of humans $53.5 \%(n=23)$ answered with yes; $32.6 \%(n=$ 14) answered with No and $14.0 \%(n=6)$ answered with Don't Know.

To give for one question the answers crosstabulated for respondents that oppose and do not oppose wearing hearing aids the results are:

- Of respondents who did not oppose wearing external hearing aids $51.4 \%(n=19)$ answered with Yes $35.1 \%(n=13)$ answered with No and $13.5 \%(n=5)$ answered with do not know.

- Of respondents who did not oppose wearing internal hearing aids $51.4 \%(n=18)$ answered with Yes $34.3 \%(n=12)$ answered with No and $14.3 \%$ $(n=5)$ answered with do not know.

- Of respondents who oppose wearing external hearing aids $(n=2) 100 \%$ answered with Yes.

- Of respondents who oppose wearing internal hearing aids $57.1 \%(n=4)$ answered with Yes $42.9 \%(n=3)$ answered with No.

To give for one question the answers cross tabulated related to how one perceives oneself and how one is perceives by others one obtains the following numbers (Table 1).

Comment given in the comment box to this question indicate that many of the respondents are skeptical whether such devices will ever appear as they feel that the devices have not even reached normal hearing quality yet. Others came up with concrete examples of what could be added to hearing devices such as greater range of frequencies, greater

Table 1 Question 13. Should we develop internal or external hearing aids that generate hearing abilities that go beyond the hearing abilities exhibited by 'normal' hearing

\begin{tabular}{llll}
\hline & Yes & No & Don't know \\
\hline Self perception: 'Normal'; Perception by others as 'Normal' & $46.7 \%(n=7)$ & $46.7 \%(n=7)$ & $6.7 \%(n=1)$ \\
Self perception: 'Normal'; Perception by others as impaired & $30.0(n=3)$ & $40.0(n=4)$ & $30.0(n=3)$ \\
Self perception: Impaired; Perception by others as 'Normal' & $66.7(n=4)$ & 0 & $33.3(n=2)$ \\
Self perception: impaired; Perception by others as impaired & $90.0 \% n=(9)$ & No $10.0 \%(n=1)$ & 0 \\
\hline
\end{tabular}


distance, heightened musical appreciation and sounds that humans cannot hear. Many also felt that if such abilities would be added to hearing aids that these devices would first be available to the hearing people.

Impact

Question 17 asks about the impact of beyond the normal hearing enabling devices on (People who belief in Deaf culture; People who perceive themselves as hearing impaired; Other disabled people of 'normal' hearing; Rehabilitation Professionals; Speech Pathology professionals; Occupational Therapy Professionals; Physical Therapy Professionals; Audiologists; Community Rehabilitation). The only group who is seen as being impacted mostly negatively $(50 \% n=21)$ is the group of people who belief in Deaf culture. For all the others a solely negative effect was below 4\%. For all groups 14-24\% of respondents saw a positive and negative effect. Other disabled people of 'normal' hearing 26.8\% $(n=$ 11) and Physical Therapy Professionals $31.7 \%(n=13)$ are the two groups seen as the most non-impacted. For the other groups the non-impacted answer was below $10 \%$. As to a solely positive impact, the numbers were between $48 \%$ and $65 \%$ for: People who perceive themselves as hearing impaired; Rehabilitation Professionals; Speech Pathology professionals; Occupational Therapy Professionals; Audiologists; Community Rehabilitation. The lowest number $14.3 \%(n=6)$ existed for People who belief in Deaf culture with second lowest $24.4 \% \quad(n=10)$ for other disabled people of 'normal' hearing.

As to the impact, covered in question 17 question 18 allowed respondents to offer their thoughts. In regards to impact on people that believe in deaf culture, 11 respondents felt that enhancement would be a threat to the continued existence of Deaf culture and people believing in Deaf culture might feel threatened. One respondent felt that the discourse would move from Deaf culture towards cyborg culture. As to people who perceive themselves as hearing impaired, the qualitative answers did mention increase of positive feelings such as self esteem $n=3$ but the comments were mostly N/A and 'it's just a nice bonus'. Two comments highlighted that the use of beyond normal enabling hearing devices might lead to a conflict with the normative hearing people. As to impact on professionals comments beside N/A centered around increased opportunity for professionals to help.

Non-hearing Related Therapeutic Devices that Enable Beyond Species-Typical Abilities

As to question 19 which asks whether therapeutic enhancement products (Brain Machine Interfaces; Artificial Hippocampus; Subvocal Speech device; Artificial Organs; Artificial Nose; Artificial Legs; Artificial Arms; Artificial Eyes; Artificial Retina; Artificial Skin) should be developed and made accessible to disabled people the Yes response rate was between $75 \%$ and $100 \%$ for all devices.

Access for Non-disabled People

As to the question whether 'non-disabled' should have access to these enhancement exhibiting therapeutic products (question 21) $24.4 \%(n=10)$ said Yes; 53.7\% $(n=22)$ said No and 22\% $(n=9)$ said Don't know.

\section{Use by Non-disabled People}

As to the question whether it can be prevented that non disabled people will use enhancement exhibiting therapeutic products (question 22) the majority 57.5\% $(n=23)$ felt that it could not be prevented with $25.0 \%$ $(n=10)$ felt they don't know and only $17.5 \%(n=7)$ felt it could be prevented. Furthermore $42.5 \%(n=17)$ felt that non-disabled people will try to obtain the devices with $35.0 \%(n=14)$ felt they don't know and only $22.5 \%(n=9)$ felt they won't.

\section{Discussion}

To data, disabled people (including deaf and hard of hearing people) and rehabilitation professionals are mostly absent from the human enhancement beyond the normal discourse. This paper presents the views of members of the World Federation of the Deaf. Although one cannot generalize the results, the views obtained give some insight as to sentiments of members of the World Federation of the Deaf. These findings might be used by the World Federation of the Deaf and other researchers to generate a survey in a form that allows for a higher response rate (e.g. through sign language), as well to engage other 
research subjects locally (e.g. through a survey, focus groups, or face to face interviews).

The key findings are that the majority believes:

a) that we should develop internal and external hearing aids that generate hearing abilities that go beyond the hearing abilities exhibited by 'normal' hearing;

b) that we should also develop other therapeutic products that enable enhancements such as brain machine interfaces; artificial hippocampus; subvocal speech device; artificial organs; artificial noses, legs arms, eyes, retina and skin;

c) that non-disabled people should not have access to enhancement exhibiting therapeutic products;

d) that one cannot prevent non-disabled people from using enhancement exhibiting therapeutic products;

e) that so called non-disabled people will try to obtain these enhancements;

f) that there will be a mostly negative impact on people who belief in Deaf culture;

g) there will be mostly positive or no impacts on people who perceive themselves as hearing impaired; other disabled people of 'normal' hearing; rehabilitation professionals; speech pathology professionals; occupational therapy professionals; physical therapy professionals; audiologists and community rehabilitation.

These results, though from a small sample, seem to support the prediction [44] that people with disabilities will move towards enhancements if available and might even push actively for such developments. It also seems to support James Hughes, the former executive director of the World Transhumanist Association, a group that promotes beyond-the-'normal' enhancements when he wrote, "Although few disabled people and transhumanists realize it yet, we are allies in fighting for technological empowerment [45]." This data strengthens the idea that as sub species-typical labelled people and people linked to them might indeed be a trailblazer for enhancements.

One highly debated topic in the enhancement discourse is whether therapeutic interventions should be accessible to so called non-disabled, healthy people [1, 31, 39, 43]. Some accept therapeutic enhancement and reject non-therapeutic enhancements. Although the survey respondents felt that 'species-typical' people should not have access to these enhancements, they also felt it unpreventable that 'species-typical' people would use enhancement exhibiting therapeutic products. They anticipate that the species-typical, the non-impaired labeled people will succeed in obtaining enhancements. The desire for enhancements might be greater the less invasive they are and the more they are reversible and easily upgradable [46]. Some might want enhancements to stay competitive in the workplace or sport or education [9, 47]; some might perceive themselves as impaired (or in a state of ill health) if they stay species-typical. They might link being healthy to having obtained all kind of enhancements [1, 48].

Given the results of the survey, what role should and can hearing related health care and rehabilitation professionals play and what actions should they take in regards to hearing beyond the normal enabling devices? Codes of ethics exist for members of many professional organizations to provide guidance as to how to act. What guidance can they give in regards to hearing beyond the normal enabling devices? The author analyzed the American Academy of Audiology [49], Academy of Doctors of Audiology ${ }^{\circledR}$ [50], Audiological Society of Australia [51], College Of Audiologists and Speech Language Pathologists [52], Canadian Association of Speech-Language Pathologists and Audiologists (CASLPA) [53] and the Standing Liaison Committee of E.U. Speech and Language Therapists and Logopedists [54] code of ethics. The codes of ethics states among others:

To keep in mind the dignity, worth, and rights of those served [49]; to protect the welfare of persons served professionally [50]; to carefully assess and document the patient's physical, social, emotional and occupational needs [50]; to inform "patients of the recommended services or products and any reasonable alternatives in a manner which allows the patient to become involved in, and make informed, treatment decisions." [50]; "The welfare of the client, students, research subjects and the public must take precedence over a member's self interest, or the interest of employers or colleagues [51]; "to choose the right, fair, good and just action" [52]; "apprise patients/clients of programs and services from which they may benefit"; [52] "The primary ethical obligation of audiologists and speech-language pathologists is to practice their skills for the benefit of their patients/ 
clients" [52]; "The welfare and dignity of those served professionally is paramount" [53]; to "contribute to the wellbeing of all individuals who access these services, in accordance with the European Convention of Human Rights" [54]; "to have respect for the autonomy and dignity of individuals" [54]; "to act in such a way as to bring benefits to individuals and to improve their quality of life" [54].

The guidance 'best interest for the person' is used by three of the five codes of ethics investigated [49, $50,54]$. It could be interpreted to obligate professionals guided by these three code of ethics to offer enhancement products to their deaf and hard of hearing clients. This is especially true if it appears that beyond species-typical hearing leads to a better quality of life for the person, or more opportunities (another guidance parameter mentioned in the code of ethics) [54]. However, quality of life has many different facets. Many different quality of life indicators exist [55-72], so which one is one to follow? The situation is further complicated by the fact that the quality of life of disabled people and the life of people linked to them is constantly underestimated (many references in [1]). Furthermore, how does the rehabilitation professional know whether the enhancement is the best way to increase the quality of life or whether some social changes might be more useful? Some caution about the constant move beyond is mentioned in Downie and Koester (2008) [73].

Linked to the theme of 'best interest of the person' is the theme of 'preventing injury and harm to the person' [49-51, 54]. These two themes together ask for a risk benefit analysis. Could the access to enhancements do more harm than good? Especially with non reversible invasive interventions could the person feel obsolete given that there might be another 'better' version coming out eventually? [46] Some of the comments of the respondents in the survey highlight that some respondents are concerned that an enhancement might change the relationship of the receiving person with others. They do not stand alone with this concern. Wolbring (2010) [46] provides the example of the World Professional Association for Transgender Health (WPATH). They have strict eligibility criteria for hormone therapy and/or genital-reconstructive surgery because of its more or less irreversibility. "The criteria include participation in psychotherapy, the requirement to live at least 1 year full-time in the preferred gender role to develop resilience in coping with the inevitable psychosocial challenges [74]." [46] The "tasks of the mental-health professional include assessment of gender identity and the impact of stigma on psychological adjustment; treatment of coexisting mentalhealth concerns; confronting internalized transphobia and grieving for the left behind gender identity [74]" [46]. The case of the WPATH raises the question whether rehabilitation professions with deaf and hard of hearing clients should be required to develop guidelines in regards to enhancements to prevent emotional harm for their clients? The enhanced deaf and hard of hearing persons might lose their bond with the non-enhanced they related to so far. The enhancement might trigger envy and they might become isolated; they might become stigmatized. They might have sensory inputs they regret later. The Nature survey [41] mentioned in the introduction highlights the danger of peer pressure. Peer pressure susceptibility is known to have an impact on the ability to refuse (see for example [75]). The above leads to the question of whether rehabilitation professionals have to start generating risk benefit analysis data around enhancement, which will be a complicated endeavor which takes some time. It might be good to start the process before the products are actually available as risk benefit calculations are not simple "putative benefits are difficult to quantify" as the report of the ethics committee of the American Academy of Neurology acknowledges [31].

Then there is the economic factor. Almost inevitably, not everyone will be able to afford the enhancements. As the report from the ethics committee of the American Academy of Neurology states: "Neuroenhancement therapies are likely to be seen as "lifestyle" drugs and therefore are unlikely to be covered by third-party payers. Whether such an inequality of distribution will provide a sufficient basis to prohibit the use of neuroenhancement at all is an issue that will have to be addressed by the medical profession and society" [31]. Indeed various codes of ethics talk about the non discrimination against their clients based on general health [49] handicapping condition [50] the nature of their illness [51] and disability [52] (whereby 53 uses disability with the meaning of impairment, defect, sub species-typical). One could interpret the wording of the code of ethics to indicate that the profession has to ensure 
access to such emerging devices for their 'impaired', sub species-typical clients as a way to minimize negative consequences (assuming that a benefit risk analysis performed concludes that the benefits are higher). For the clients that cannot obtain enhancement products, they might have to find ways to minimize the detrimental effects linked to not being enhanced.

The prohibition of discrimination of services based on general health opens the door for the profession having to serve also the so-called species-typical hearing people with enhancement devices if they wish so. If devices which enhance hearing used by deaf and hard of hearing people lead to some advantages, a so-called normal hearing person could claim that their general health is affected due to decrease in opportunity i.e. employment due to a lack of competitiveness. As such, the person could seek the devices to 'level the playing field.'

\section{Conclusion}

Given that (a) increasing ability, access to, demand for, and acceptance of changing, improving, modifying and enhancing the human body in terms of its structure, function or capabilities beyond its Homo sapiens-typical boundaries leads to a changed understanding of oneself, one's body, and one's relationship with others of the species, other species and the environment [1, 16, 41, 48, 76-79], (b) the answers by the survey respondents and (c) the themes of responsibility evident in the codes of ethics, it might be pertinent that the enhancement discourse is discussed more broadly by more stakeholders. It additionally might be prudent to develop guidelines on the enhancement topic such, as was developed by the American Academy of Neurology [31]. However, the development of guidelines has to be accompanied by a broad discourse within a given profession that includes their clients. It's time that a broad discourse starts within the disability community because if one disability group accepts a push for enhancements this will impact other groups within the disability community. Furthermore a broad societal discourse on enhancements and the goals that drive their use is needed. The report from the ethics committee of the American Academy of Neurology seems not to have triggered a broad response so far, although some comment were generated [80].
Acknowledgments This work was in part supported by a Social Sciences and Humanities Research Council standard operating grant.

Open Access This article is distributed under the terms of the Creative Commons Attribution Noncommercial License which permits any noncommercial use, distribution, and reproduction in any medium, provided the original author(s) and source are credited.

\section{References}

1. Wolbring, G. 2005. HTA initiative \#23. The triangle of enhancement medicine, disabled people, and the concept of health: A new challenge for HTA, health research, and health policy. Edmonton: Alberta Heritage Foundation for Medical Research, Health Technology Assessment Unit.

2. Boorse, C. 1977. Health as a theoretical concept. Philosophy of Science 44(4): 542-573.

3. Boorse, C. 1975. On the distinction between disease and illness. Philosophy and Public Affairs 5(1): 49-68.

4. Wade, D.T., and B.A. de Jong. 2000. Recent advances in rehabilitation. BMJ 320(7246): 1385-1388.

5. Griffiths, E.H. 1940. Rehabilitation. British Medical Journal 2(4163): 536-537.

6. Medical Dictionary. 2009. Rehabilitation. Medical dictionary. http://medical-dictionary.thefreedictionary.com/ Rehabilitation. Accessed 10 May 2011.

7. Stucki, G., A. Cieza, and J. Melvin. 2007. The international classification of functioning, disability and health: A unifying model for the conceptual description of the rehabilitation strategy. Journal of Rehabilitation Medicine 39(4): 279-285.

8. Zettler, P.J. 2009. Is it cheating to use cheetahs: The implications of technologically innovative prostheses for sports values and rules. Boston University International Law Journal 27: 367-409.

9. Wolbring, G. 2008. Oscar Pistorius and the future nature of olympic, paralympic and other sports. SCRIPTed-A Journal of Law, Technology \& Society 5(1): 139-160.

10. International Paralympic Committee. 2008. IPC Position statement on IAAF's commissioned research on Oscar Pistorius. International Paralympic Committee. http://www. paralympic.org/release/Main_Sections_Menu/News/Press_Releases/2008_01_14_a.html. Accessed 10 May 2011.

11. The Courts of Arbitration for Sport (the "CAS"). 2008. CAS 200S/A/14S0 Pistorius v IAAF Arbitral award. The Court of Arbitration for Sport (the "CAS"). http://jurisprudence. tas-cas.org/sites/caselaw/shared\%20documents/1480.pdf. Accessed 10 May 2011.

12. Swartz, L., and B. Watermeyer. 2008. Cyborg anxiety: Oscar Pistorius and the boundaries of what it means to be human. Disability \& Society 23(2): 187-190.

13. Romon, R. 2010. Double amputee Aimee Mullins' prosthetic limbs make her sexier and faster than you. Technocrati. http:// technorati.com/technology/article/double-amputee-aimeemullins-prosthetic-limbs/\#ixzz15qj5vSjr. Accessed 10 May 2011. 
14. TED Talks. 2010. Aimee Mullins and her 12 pairs of legs. TED talks. http://www.ted.com/talks/aimee_mullins_ prosthetic_aesthetics.html. Accessed 10 May 2011.

15. Ironman Triathlon. 2010. Sara Reinertsen-Ironman Finisher. Ironman Triathlon. http://www.youtube.com/ watch?v=-qMz0QwyqPw. Accessed 10 May 2011.

16. Coenen, C., M. Schuijff, M. Smits, P. Klaassen, L. Hennen, M. Rader, et al. 2009. Human enhancement study. European Parliament. Report no.: (IP/A/STOA/FWC/ 2005-28/SC35, 41 \& 45) PE 417.483.

17. Cheung, E.H. 2010. Psychiatry in the era of neuroethics. Psychiatric Times 27(6).

18. Ambient Corp. 2009. Wheelchair demonstration. Ambient Corp. http://www.theaudeo.com/tech.html. Accessed 10 May 2011.

19. Cascio, J. 2007. The accidental cyborg. Open the future blog. http://openthefuture.com/2007/06/the_accidental_ cyborg.html. Accessed 10 May 2011.

20. Fat Knowledge. 2006. Pimp my cochlear implant. Fat knowledge blog. http://fatknowledge.blogspot.com/2006/ 04/pimp-my-cochlear-implant.html. Accessed 10 May 2011.

21. Citi, L., O. Tonet, and M. Marinelli. 2009. Chapter 15 matching brain-machine interface performance to space applications. International Review of Neurobiology 86: 199-212.

22. Clausen, J. 2009. Man, machine and in between. Nature 457(7233): 1080-1081.

23. Yokoi, H. 2009. Cyborg (brain-machine/computer interface). Advanced Robotics 23(11): 1451-1454.

24. Colker, R. 2007. Anti-subordination above all: A disability perspective. Notre Dame Law Review 82(4): 1415-1483.

25. Sparrow, R. 2005. Defending deaf culture: The case of cochlear implants. Journal of Political Philosophy 13(2): 135-152.

26. Gaines, R.A. 2003. The value of deaf culture: Should states have the right to mandate placement of cochlear implants? Current Surgery 60(6): 600-601.

27. Hladek, G.A. 2002. Cochlear implants, the deaf culture, and ethics: A study of disability, informed surrogate consent, and ethnocide. Monash Bioethics Review 21(1): 29-44.

28. Lane, H., and B. Bahan. 1998. Ethics of cochlear implantation in young children: A review and reply from a deaf-world perspective. Otolaryngology-Head and Neck Surgery 119(4): 297-313.

29. Tucker, B.P. 1998. Deaf culture, cochlear implants, and elective disability. Hastings Center Report 28(4): 6-14.

30. Blume, S.S. 2010. The artificial ear: Cochlear implants and the culture of deafness. Rutgers Univ Pr.

31. Larriviere, D., M.A. Williams, M. Rizzo, and R.J. Bonnie. 2009. Responding to requests from adult patients for neuroenhancements. Neurology 73(17): 1406.

32. Young, A., M. Grey, C.J. Boyd, and S.E. Mccabe. 2011. Adolescent sexual assault and the medical and nonmedical use of prescription medication. Journal of Addictions Nursing 22(1-2): 25-31.

33. Boyd, C.J., A. Young, M. Grey, and S.E. Mccabe. 2009. Adolescents' nonmedical use of prescription medications and other problem behaviors. Journal of Adolescent Health 45(6): 543-550.

34. Teter, C.J., S.E. Mccabe, C.J. Boyd, and S.K. Guthrie. 2003. Illicit methylphenidate use in an undergraduate student sample: Prevalence and risk factors. Pharmacotherapy 23(5): 609-617.

35. Rabiner, D.L., A.D. Anastopoulos, E.J. Costello, R.H. Hoyle, S.E. Mccabe, and H.S. Swartzwelder. 2009. The misuse and diversion of prescribed ADHD medications by college students. Journal of Attention Disorders 13(2): 144-153.

36. Rabiner, D.L., A.D. Anastopoulos, E.J. Costello, R.H. Hoyle, S.E. Mccabe, and H.S. Swartzwelder. 2009. Motives and perceived consequences of nonmedical ADHD medication use by college students are students treating themselves for attention problems? Journal of Attention Disorders 13(3): 259-270.

37. Mccabe, S.E., C.J. Boyd, J.A. Cranford, and C.J. Teter. 2009. Motives for nonmedical use of prescription opioids among high school seniors in the United States selftreatment and beyond. Archives of Pediatrics \& Adolescent Medicine 163(8): 739-744.

38. Forlini, C. 2009. Examining discourses on the ethics and public understanding of cognitive enhancement with methylphenidate. Dissertation University of Montreal. https://papyrus.bib.umontreal.ca/jspui/bitstream/1866/2804/ 4/Forlini_Cynthia_2008_memoire.pdf. Accessed 10 May 2011.

39. Geppert, C.M.A., and P.J. Taylor. 2011. Should psychiatrists prescribe neuroenhancers for mentally healthy patients? Psychiatric Times 28(3).

40. Capps, B. 2010. Libertarianism, legitimation, and the problems of regulating cognition-enhancing drugs. Neuroethics. doi:10.1007/s12152-010-9059-3.

41. Nature. 2008. Poll results: Look who's doping. Nature 452: 674-675.

42. Outram, S.M., and E. Racine. 2011. Developing public health approaches to cognitive enhancement: An analysis of current reports. Public Health Ethics 4(1): 93.

43. Banjo, O.C., R. Nadler, P.B. Reiner, and J. Priller. 2010. Physician attitudes towards pharmacological cognitive enhancement: Safety concerns are paramount. PloS One 5 (12): e14322.

44. Wolbring, G. 2004. Solutions follow perception: Nano-BioInfo-Cogno-technology (NBIC) and the concept of health, medicine, disability and disease. Alberta Health Law Review 12(3): 41-47.

45. Hughes, J. 2004. Battle plan to be more than well transhumanism is finally getting in gear. World Transhumanist Association Webpage. http://transhumanism.org/ index.php/th/more/509/. Accessed 10 May 2011.

46. Wolbring, G. 2010. Obsolescence and body technologies Obsolescencia y tecnologías del cuerpo. Dilemata International Journal of Applied Ethics 2(4): 67-83.

47. Wolbring, G. 2008. One world, one olympics: Governing human ability, ableism and disablism in an era of bodily enhancements. In Human futures: Art in the age of uncertainty, ed. Andy Miah. Liverpool: Liverpool University Press.

48. Wolbring. G. 2010. Nanotechnology and the transhumanization of health, medicine, and rehabilitation. In: 
Controversies in science and technology volume 3: From evolution to energy, ed. David Lee Kleinmann, Delborne Jason, Cloud-Hansen Karen, Handelsman Jo, 286-98. Leibert.

49. American Academy of Audiology. 2010. Code of ethics. http://www.audiology.org/resources/documentlibrary/ Pages/codeofethics.aspx?PF=1. Accessed 10 May 2011.

50. Academy of Doctors of Audiology. 2010. Code of ethics of the Academy of Doctors of Audiology ${ }^{\circledR}$. Academy of Doctors of Audiology. http://www.audiologist.org/academy-documents/ code-of-ethics.html. Accessed 10 May 2011.

51. Audiological Society of Australia. 2002. Code of ethics. Audiological Society of Australia. http://www.audiology. asn.au/. Accessed 10 May 2011.

52. College of Audiologists and Speech Language Pathologists. 2010. Code of ethics. College Of Audiologists and Speech Language Pathologists. http://www.caslpo.com/Practice Standards/CodeOfEthics/tabid/102/Default.aspx. Accessed 10 May 2011.

53. Canadian Association of Speech-Language Pathologists and Audiologists (CASLPA). 2005. Code of Ethics. Canadian Association of Speech-Language Pathologists and Audiologists (CASLPA). http://www.caslpa.ca/PDF/ code $\% 20$ of $\% 20$ ethics.pdf. Accessed 10 May 2011.

54. Standing Liaison Committee of E.U. Speech and Language Therapists and Logopedists. 2010. A framework for ethical practice in speech and language therapy. Standing Liaison Committee of E U Speech and Language Therapists and Logopedists. http://www.cplol.eu/eng/ethical_practice.htm. Accessed 10 May 2011.

55. Ku, P.W., K.R. Fox, and J. McKenna. 2008. Assessing subjective well-being in Chinese older adults: The Chinese aging well profile. Social Indicators Research 87(3): 445-460.

56. Grasso, M., and L. Canova. 2008. An assessment of the quality of life in the European Union based on the social indicators approach. Social Indicators Research 87(1): 1-25.

57. Calvert Group LaHH. 2005. The Calvert-Henderson quality of life indicators.

58. Bohnke, P. 2008. Does society matter? Life satisfaction in the enlarged Europe. Social Indicators Research 87(2): 189-210.

59. Narayana, M.R. 2009. Education, human development and quality of life: Measurement issues and implications for India. Social Indicators Research 90(2): 279-293.

60. Nord, E. 1991. EuroQol: Health-related quality of life measurement. Valuations of health states by the general public in Norway. Health Policy 18(1): 25-36.

61. Veenhoven, R. 1996. Happy life-expectancy-A comprehensive measure of quality-of-life in nations. Social Indicators Research 39(1): 1-58.

62. Renn, D., N. Pfaffenberger, M. Platter, H. Mitmansgruber, R.A. Cummins, and S. Hofer. 2009. International wellbeing index: The Austrian version. Social Indicators Research 90(2): 243-256.

63. Rossouw, S., and W. Naude. 2008. The non-economic quality of life on a sub-national level in South Africa. Social Indicators Research 86(3): 433-452.

64. Chen, Z.H., and G. Davey. 2008. Normative life satisfaction in Chinese societies. Social Indicators Research 89(3): $557-564$.
65. Liao, P.S. 2009. Parallels between objective indicators and subjective perceptions of quality of life: A study of metropolitan and county areas in Taiwan. Social Indicators Research 91(1): 99-114.

66. Costanza, R., B. Fisher, S. Ali, C. Beer, L. Bond, R. Boumans, et al. 2007. Quality of life: An approach integrating opportunities, human needs, and subjective well-being. Ecological Economics 61(2-3): 267-276.

67. Birnbacher, D. 1999. Quality of life-evaluation or description? Ethical Theory Moral Practice 2(1): 25-36.

68. Shu, X.L., and Y.F. Zhu. 2009. The quality of life in China. Social Indicators Research 92(2): 191-225.

69. Moro, M., F. Brereton, S. Ferreira, and J.P. Clinch. 2008. Ranking quality of life using subjective well-being data. Ecological Economics 65(3): 448-460.

70. Moller, V., and H. Dickow. 2002. The role of quality of life surveys in managing change in democratic transitions: The South African case. Social Indicators Research 58(1-3): 267-292.

71. Somarriba, N., and B. Pena. 2009. Synthetic indicators of quality of life in Europe. Social Indicators Research 94(1): 115-133.

72. Distaso, A. 2007. Well-being and/or quality of life in EU countries through a multidimensional index of sustainability. Ecological Economics 64(1): 163-180.

73. Downie, M., and R. Koestner. 2008. Why faster, higher, stronger isn't necessarily better-The relations of paralympian and women's soccer teams' performance to national well-being. Social Indicators Research 88(2): 273-280.

74. Bockting, W.O. 2008. Psychotherapy and the real-life experience: From gender dichotomy to gender diversity. Sextologies 17(4): 211-224.

75. Flannery, D.J., A.T. Vazsonyi, J. Torquati, and A. Fridrich. 1994. Ethnic and gender differences in risk for early adolescent substance use. Journal of Youth and Adolescence 23(2): 195-213.

76. Wolbring, G. 2008. Ableism, enhancement medicine and the techno poor disabled. In Unnatural selection: The challenges of engineering tomorrow's people, ed. Peter Healey and Rayner Steve, 196-209. London: Earthscan.

77. Roco, M., and W. Bainbridge. 2003. Converging technologies for improving human performance: Nanotechnology, biotechnology, information technology and cognitive science. Dordrecht: Kluwer Academic.

78. Word Transhumanist Association. 2005. What is Transhumanism? http://www.transhumanism.org/resources/ transhumanism.htm. Accessed 10 May 2011.

79. Williams, A.E. 2006. Good, better, best: The human quest for enhancement summary report of an invitational workshop convened by the scientific freedom, responsibility and law program American association for the advancement of science June 1-2, 2006. American Association for the Advancement of Science (AAAS). http://www.aaas.org/ spp/sfrl/projects/human_enhancement/pdfs/HESummary Report.pdf. Accessed 10 May 2011.

80. Racine, E., and C. Forlini. 2010. Responding to requests from adult patients for neuroenhancements: Guidance of the ethics, law and humanities committee. Neurology 74 (19): 1555. 